Journal of Engineering and Applied Sciences 15 (6): 1393-1401, 2020

ISSN: 1816-949X

(C) Medwell Journals, 2020

\title{
Monuments: E-San Social and Culture Reflection
}

\author{
${ }^{1}$ Sriphat Thesarin, ${ }^{2}$ Burin Plengdeesakul and ${ }^{2}$ Preechawute Abhirating \\ ${ }^{1}$ Faculty of Humanities and Social Sciences, Rajabhat Maha Sarakham University, \\ Nakhon Sawun Road, Talat Sub-District, Muang District, \\ 44000 Bangkok, Mahasarakham Province, Thailand \\ ${ }^{2}$ Faculty of Fine and Applied Arts, Khon Kaen University, Muang District, \\ 40002 Bangkok, Khon Kaen Province, Thailand
}

\begin{abstract}
This research aims to study the history of monuments in the Northeastern region, study the current state of monuments in the Northeastern region and study the social and culture reflection of E-San through monuments using a qualitative research process, document and field data collection by surveys, observation, interviews and group discussions. Data collection is processed for analysis using aesthetics theory, structural functionalism theory, cultural diffusion theory, conflict theory and symbolic interactionism theory. Study findings are presented in descriptive analysis with illustrations. Research results found that the history of monuments created by the concept of local E-San people themselves, not a government concept. It was first appeared in the year 1968, namely, Chaopho Si Nakhon Tao Monument at Ban Mueang Tao, Mueang Tao subdistrict, Phayakkhaphum Phisai district, Maha Sarakham province. From that time, the creation of monuments of important people has expanded throughout the Northeast and popularly created until now. It can be classified into 2 groups of persons that are created as monuments: historical persons legendary persons. The study found that the legendary group of persons is used to create monuments the most. Regarding current conditions of the monument, for the location aspects, it's found that most of the monuments are located in the public area of the community such as the ancestral spirit forest (Don Pu Ta), located on the north side of the community facing the East. The layout of the monument comes in two types: an independent layout and a rectangular layout. The research found most of the monuments are rectangular layouts. For the shape of the monument, it looks similar to a person, showing gestures in both sitting and standing positions. Cement is preferably used as construction material as well as stone and brass. Construction techniques are usually fresh mortar molding techniques, stone carving and brass casting. For the E-San social and culture reflection aspects, the study found that the monument can reflect E-San society in the social collective memories. It can also represent power relations, conflict and contention in the management of monuments among people in the community and also plays a role in the sanctification of the rituals in the community, while helping to support the community agriculture cycle. In addition, it comes with a function to control the society and create social unity. For cultural reflection, people believe that monuments are sacred, a mental refuge and inspire fortune as desired. People also believe that a monument is the place where souls of the ancestral spirits is at. Therefore, there is an annual worship offering to express faith to the monument with both personal and community rituals. The monuments can therefore, reflect the E-San society and culture at some extents.
\end{abstract}

Key words: Monuments, E-San social and culture, E-San social and culture reflection, inspire, community

\section{INTRODUCTION}

A monument is something a man created to commemorate a person with goodness, so that, the future generations can see. There are many styles of monuments both physical and abstract as well as architectural sculptures, this includes various important places that can be a remembrance of a person or important events. The creation of monuments of important persons is popular throughout the world and has been built for thousands of years, since, Roman times with both marble and bronze sculptures, the evidence of these sculptures has still existed until these days. This indicates the strength and stability for a period of thousands of years (Namkaew, 2013). The creation of a monument of a person in Thailand has appeared, since, the Ayutthaya period, it was a statue of Phra Thep Bidon (holy deity-father) which is believed to be a statue of King U Thong. In addition, the Royal Chronicles of Ayutthaya also mentioned a statue of King Naresuan the Great which is enshrined in the arsenal. In the Rattanakosin period, King Rama III graciously created carved self-images of Nai Nok and Nai

Corresponding Author: Sriphat Thesarin, Faculty of Humanities and Social Sciences, Rajabhat Maha Sarakham University, Nakhon Sawun Road, Talat Sub-District, Muang District, 44000 Bangkok, Mahasarakham Province, Thailand 
Rueang who burned themselves to death which was the motto of creating a monument of a person according to the old motto of worshipping. The creation of royal monuments and monuments of living persons was first started in the reign of King Rama IV (Eoseewong, 1990). The first royal monument in Thailand that was built in a public place and open for people to worship is the royal monument of King Chulalongkorn which is located at the Dusit Palace, a.k.a. Equestrian Statue Rama V' is located in the courtyard of Dusit Palace Royal ground. The royal statue was built in the reign of King Rama V by taking the example from the statue of King Louis XIV of France in Paris, built with French craftsmen when the casting was completed, it was moved to be enshrined in Thailand (Aruninta, 2005). After that, the western-styled monument became widespread in Thailand, especially, during the reign of King Rama VI who had a royal desire to get a sculptor to help build monuments. This resulted in that Professor Silpa Bhirasri, formerly known as Corrado Feroci, an Italian born in Florence, graduated from the Royal Art Academy of Florence. He came to Thailand to apply for government service in the year 1923 as a sculptor for the Fine Arts Department (Tatiya, 2006), the work of monumental sculptures of Professor Silpa Bhirasri, before the democratic revolution in 1932 was the statue of King Rama I the great. In the old days, people who had monuments as memorials were only the Kings, monarchs or noble persons. The monument will only be created in accordance with only the King's royal orders. However, after the change in the government regime in 1932, common people were able to have monuments as memorials. The first monument of a common person in Thailand is Thao Suranaree Monument or Khunying Mo, Nakhon Ratchasima heroine, built in 1934 which is considered to be the first monument of a common person in Thailand and the E-San region (Kaewngamprasert, 1994).

After the change in the government regime in 1932, the creation of monuments became increasing and spread in many areas of the country. Reasons why creating monuments of important people became popular in these areas may be due to two reasons: the idea of heroes and the emergence of the agency directly responsible for building monuments, namely the Fine Arts Department (Khumsupha, 2005). The increasing number of monuments indicated that the role of the monument has been more accepted as it can be considered as a building that has a significant effect on political symbols. Contents and style of the monuments are always considered and determined by the government because the monument has the qualities of communicating, inviting or being called as propaganda, motivating people and society very well. Therefore, the characteristics of the monuments that appear in that particular era can reflect very well the image of society at that time whether there is a group of ideas or what political groups influencing in the society (Prakit Nontawith, 2007).

For the Northeastern region, the creation of images of people who are not religious idols was first appeared in the 18th century during the era in which the Northeastern region was under the political and cultural influence of the Khmer era. During that period, the said-images of a person usually referred to the image of the royal garments of Jayavarman VII and the statue of Jayarachadevi, Consort of Jayavarman VII. The images of the two garments were discovered at Prasat Hin Phimai in Nakhon Ratchasima province which villagers in the area respected and believed to be the image of Thao Pachit and Nang Oraphim, the characters in a folk tale that was told in the area of Nakhon Ratchasima. These two images of royal garments are assumed to be built under the royal command of Jayavarman VII, to be worshiped by the local people under his rule. The images are regarded as the king's power. Therefore, images of noble persons was found scattered throughout the Khmer Empire during this period. The images of the royal garments of Jayavarman VII and that of Jayarachadevi do not have any connection with the monument to represent a person in the present sense. The monument that represents a person in the present sense that first appeared in the Northeastern region, created under a concept of the state is Thao Suranaree MONUMENT or aka, Khun Ying Mo which is enshrined at Chumphon Gate, Nakhon Ratchasima province. It is the first monument of a common person in the Thai history. Thao Suranaree monument is sculpted by Professor Silpa Bhirasri with opening ceremony on 16 January 1934. At present, besides being a monument of national heroines, the monument of Thao Suranaree also has a status as a city god as well (Kaewngamprasert, 1994).

The creation of a statue of a person who is a common person under the concept of the state was raised up for the reason to spread the nationalistic feelings to the people and to communicate the concrete concept using the monument as a tool. As appeared in the media film of the government of Khana Ratsadon (People's Party) dated 4 November, 1935 by assigning the Office of the Prime Minister to educate the people about nationalism. One of the strategies is to cast a monument to the one who has made good deeds for the nation or to sacrifice for the nation. To do this, there is no exception whether it is a man or a woman, the rich or the poor, the government should honor that person to be an example for other people. No reward is better than casting a monument of that person at the place where the person was born or has done good deeds. If that person had made the greatest benefit that no one else can to the nation, then the monument should be casted in the middle of the city or 
the city hall of every province as the government has already done before (Gor Jor Chor. (2) Sor Ror. 0201.10/31 with reference to Kaewngamprasert, 1994). With this concept, after the monument of Thao Suranaree, it appeared to have many other monuments built under the concept of the state in many Northeastern regions such as the Monument of Phraya Surin Phakdi Si Narong Changwang, Mayor of Surin, monument of Phraya Phakdi Chumphon, Mayor of Chaiyaphum, Monument of Phraya Chai Sunthon, Mayor of Kalasin, monument of Phra Prathum Worarat Suriyawong, Mayor of Ubon Ratchathani, for instance.

Later, the creation of monuments, according to the concept of Khana Ratsadon (People's Party), expanded into the realization of the local people who then applied this concept to create a monument to represent a person that the local people respect or look up to which can be either the city builder, the defender or as a spiritual leader. It is a monument formed under the concept of local villagers, built by local technicians and with the cooperation of the local community itself. The survey study witnessed that the monuments created according to the said concept are found scattered in many areas of the Northeast which mostly relates to communities in the Tai-Lao culture group and the Mon-Khmer culture group-the groups that have evidenced the establishment of the community since the end of the Ayutthaya period and continued until the Rattanakosin period, especially, the people who migrated or were forcibly brought into the reign of King Rama III. A monument representing a person, created under the concept of the local people themselves all play an important role in the way of lives of the people in the community. The researcher considers there are many interesting issues in both the history, social and cultural dimensions and the dimension of the local technician workmanship. With such importance of monuments, the study titled "Monuments : E-San Social and Culture Reflection” aims to study about the history, current conditions and reflection of E-San society and culture by studying through monuments and surrounding contexts in order to gain new body of knowledge about monuments in the Northeastern region and to be useful for the study of monuments of the nation.

\section{Objectives:}

- To study the history of monuments in the Northeastern region

- $\quad$ To study the current conditions of the monuments in the Northeastern region

- $\quad$ To study the E-San social and culture reflection in the monuments

\section{MATERIALS AND METHODS}

The study of "Monuments: E-San social and culture reflection" is a qualitative research. For the target group, the researcher divided the target groups into 2 groups, namely, the target group that are the monument and target group that are individuals. For the target group of 55 monuments, the selection criteria are: study only monuments that are held annually for worshiping ceremonies, study only monuments that are built under the concept of the local E-San people, not a concept of technician or the state's concepts and study only monuments with myths or history relative to the area where the monument is located. As for the target group of individuals, it consists of 32 knowledgeable groups, namely community leaders, local philosophers, 25 groups of operators who are monument designers, technicians who built the monuments, ritual leaders and A group of 55 people involved, people living in monument areas, monument administrator. Research tools used in data collection include survey questionnaires, observations, interviews and group discussions. For data collection, the researcher collected information consistent with the objectives set-forth. There are two methods for the data collection: collecting data from research papers of the government, educational institutions, books, textbooks, thesis and the internet and field data collection using survey methods, observation, interviews and group discussions. Achieved data will be processed and analyzed an analysis of data from documents using the method of agreement which consists of conceptual validation and theory validation. Field data analysis is the analysis of data obtained from using all types of tools for data collection to create a conclusion using 3 types of analysis: concrete analysis, analysis by using theory as a classification, data classification using cultural diffusion theory, structural functionalism theory, aesthetics theory, symbolic interactionism theory and conflict theory for the classification of information including the non-theoretical analysis and data analysis by comparing data-data comparison according to events or phenomena that occur. Presentation of the results of the analysis is processed using descriptive analysis, along with table charts, photographs and line drawings.

\section{RESULTS AND DISCUSSION}

History of the monuments in the Northeast: From the study of monuments in the Northeastern region, targeting a total of 55 monuments, created by the concept of non-governmental body or the Fine Arts Department but the local communities themselves. The study found that the oldest monument is the Chao Pho Srinakhon Tao monument, located at Ban Mueang Tao, Mueang Tao Sub-district, Phayakkhaphum Phisai district, Maha Sarakham province. This monument was built in 1968 by concept of the local people. The latest monument is Khun Khongrit monument located at Ban Dan, Dan sub-district, Rasi Salai district, Sisaket province, created in the year 2018. If counting the time of building a 
monument by the concept of a local that is not created by the government, since, the first monument erected in the year 1968 until the year 2018, it has been counted for 50 years and if the monument is divided into 10 years periods or divided into 1 decade, it is found that during the first decade, from 1968-1977, only 2 monuments were erected and there was a period of construction between the first and second images which were 9 years apart. In the first phase, the monument of a person is not yet popular in the creation by the local people due to the lack of sculptors and budget. Then, in the second decade of the year 1978-1987, there was a tendency to create more monuments in 5 places. During the 3rd decade of 1988-1997, 6 additional monuments were built. During the 4th decade of 1998-2007, there are 13 additional monuments being erected. During the 5th decade of 2008-2018, the largest number of monuments is found to have been created with the number of 25 locations. The division of these decades has a tendency to build more monuments by a group of technicians who built a monument that are mostly technicians in the Northeastern area. They come in both professional craftsmen and other occupations but possess some skill in molding. The monuments in the Northeast can be divided into 2 groups: monuments of people in history which are 10 places and monuments of legendary persons which are 45 places. These groups are ancestors groups such as grandparents. Building monuments in the E-San region preferably represents the legendary persons to create monuments the most. The idea of creating a monument of this legendary group of people was to give a concrete identity to those people using symbols to represent this group of people. A small wooden mini-temple is usually created before building a monument, some communities carved wooden logs into dolls while some communities use stone as a symbol.

\section{Current conditions of monuments in the Northeast:} The study of the current conditions of the monuments in the Northeastern region is divided into 4 aspects including the location for the monument, it's found that most of the monuments are located in the ancestral spirit forest (Don $\mathrm{Pu} \mathrm{Ta}$ ) and the community public areas. The Don $\mathrm{Pu}$ Ta area is considered an important and sacred area to the communities in the Northeast, most of which are located outside the community. For the monument layout, it was found that there were 2 patterns, namely a rectangular layout and an independent layout. It's found most monuments have a rectangular layout. For the location of the monuments, the study found that most monuments locate to the north of the community with the number of 22 places found, followed by the south of the community 15 places, 11 places is found in the East. The lowest number of the monuments is found in the west of the community, only 7 locations. For the location of the monuments located outside the community, there are 24 places while there are 31 monuments that are located in the community. The 4 monuments are located on hills, while the remaining number of 41 monument is located on a flat area. Regarding the direction the monuments are facing at, the most popular direction for the monuments, is facing to the East with the number of 21 while the second is the west with the number of 13 monuments facing the South at 11 monuments while facing the North, 10 , the smallest number. Regarding the shape of the monument, the entire number of monuments look like a person, divided into 18 standing positions, 37 sitting positions. The size and scale of a monument ranges from the size of a real person, to bigger than a real person or with a height of $70-280 \mathrm{~cm}$. The color of the monument is divided into 2 groups, consisting of group 1 , the color that is the color of the material used to build the monument such as sandstone carved monuments and group 2, monuments that use the process of new coloring on the surface of the monument. The base of the monument is divided into 2 types-type 1 which has a platform as the base, has the number of 35 monuments and type 2, a monument without a platform, 20 monuments. Other decorated items in a monument include sword which is considered to be the most common element found at 16 monuments, followed by walking stick, found at 12 monuments. For materials and techniques in the monument building, the most popular material for building a monument is cement, followed by stone, whereas those constructed with brass are the lowest in number. The most popular technique for creating a monument is fresh mortar molding techniques, followed by stone carving and brass casting.

Reflections on E-San society and culture in monuments: For the reflections on E-San society, the monument is something that people in the community created to symbolize the remembrance of the goodness of the people who have created for the community, society and the nation. After the creation of the monument, it has caused various phenomena related to monuments that can reflect the image of E-San society which consists of creation of social collective memories, the monument is a symbol that reflects the memories of people in the past about important events that will make people remember the stories or events that have happened in the past. Creating social collective memories of the people through rituals celebrated annually, this brings the past events for the people to see again. This is considered to be a reproduction of the social memories for all the people in the community. In relation to power relations, conflict and contention, when a monument was built, it causes many groups to become more involved, the more famous is a monument, the more people have faith in it, so having a reputation for being vowed and achieving success. This 
will bring the faith of the people to the monument, thus, making money from donations, resulting in benefits that make people want to take over the management which results in a fight for a chance to get the power to manage. This will eventually cause conflicts in the community. This reflection is witnessed now in many monuments in the Northeast. For the aspect of role of the monument to the community, divided into direct function, the monument is the sanctification of community rituals as it is considered a sacred place for the community. Anytime there are going to have traditional festivals in the community, it must be informed to this sacred place in order for the activities or merit to complete successfully. For the role in supporting the community agriculture, the ritual is a symbol that the E-San society was created to show gratitude and reverence for the ancestral spirits that inspire the cultivation of rice farming, for the sake that the farmers may get successful in productivity. Looking at the aspect of latent function of a monument to the community, it is considered a way to control the society by virtue of supernatural power, causing people to be afraid of being punished when doing something against the good tradition of the society. This is to create the unity of society by holding a monument as a community center for organizing various traditional events each year.

E-San culture reflection in the monument: For local beliefs related to the monument, it consists of sacredness, solemn promises and fortune blessing. According to beliefs and faith that people have for the monument, they believe that the monument has the soul of the ancestral spirits that resides in it, then causing ritual worship. Therefore, it reinforces the monument to increase its sacredness much more. Psychological dependence, believing in supernatural things beyond scientific explanation has been with humans for a long time and will continue to exist because nowadays, even though technology has progressed, there are some situations which still have no answers scientifically. People then still believe in having faith in morale and get an encouragement from the invisible things and cannot be proven. These are beliefs about psychological dependence, being reflected through rituals giving to the monuments and beliefs about ancestral spirits, it is the belief that appears the most when building a monument, especially, the monuments originated from legendary persons including ancestral spirits such as grandparents, grandchildren, deities. When building these monuments, it even more emphasizes the belief in the ancestral spirits of E-San society. Believing in the same group of people, paying respects to the same spirits, all reflect the strong beliefs of the E-San's world view towards the supernatural and the spirits of ancestral spirits.

For rituals held for monuments, there are both personal ceremonies and communal ceremonies. There are 5 elements of the ritual consisting of place of ritual consists of monuments of historical persons; the place for holding that ritual is related to that person's history and important places. For the legendary monument group, consisting of a group of ancestors such as grandmother, grandfather, deities, this is a group of local monuments created by the concept of people in the community themselves and will have locations related to the location where San $\mathrm{Pu}$ Ta (ancestral spirit house) is or in the area of the community's ancestral spirit forest (Don Pu Ta). For the persons related to holding the rituals, the study found that leaders in ritual can be divided according to the group of monuments which are a monuments of historical persons. For this group, leaders in the ritual are preferably senior or a knowledgeable person who has expertise in various ritual processes related to monuments. For a group that is a legendary person which is a group related to ancestral spirits, ghosts of the community, this group will have a ritual leader who is called Thao Cham (spirit operator) to lead the ritual. For the objects used in the ritual, this includes offerings such as flowers, incense, candles, Khan 5 and Khan 8 (offering bowl or platter). These objects used in rituals is when the people want to inform what they are going to do or to make a solemn promise or for making a votive offering, using particularly the objects as it has been vowed. For the objects used in the community ritual, this includes offerings such as candles, incense, flowers as well as sacrifices such as Bai $\mathrm{Si}$, betel quid, garland, colorful fabrics, holy water, drinking water, liquor, fruits, savory and sweet dishes. Bringing sacred objects to be used in the rituals expresses abundance and the prosperity that will happen to the people themselves, family and the community. For the duration of the ritual for a monument, it is divided into 2 groups, consisting of groups that are monuments of historical persons which most of the ritual dates are related to the important days of that particular person, such as birthdays, death dates. For the monuments that are of legendary person, this group does not exist in the real history and most of them are monuments that their own identity are created from the local's belief in the grandfather's ghost or belief in the ancestral spirits of the E-San society, the feast day or the sacrificial day, therefore, falls on the day they usually feast the ancestral ghosts. The 1st feast of the year is preferably any day in the 6 th month or the pre-farming season while the 2nd feast of the year is preferably in the 3rd month or after the harvest. The date and time of the rituals remarkably reflect the social and cultural beliefs of the Northeastern region about the relationship of time and ritual traditions of Heet 12 of the Northeast. The process and sequence in the ritual related to the monuments, in the Northeastern region, it can be divided into 2 types which are the non-complicated process and sequence and the complicated process and sequence. The non-complicated 
process and sequence in a ceremony are rather a personal ritual which are making a solemn promise, making a votive offering whereas the complicated process and sequence are rather the community rituals, consisting of the annual worship ceremony for the monument.

In accordance with concepts of creating monuments of a person in E-San communities that are not governmental concepts, the study found that the use of legendary group of persons was used the most as the model for the creation. This corresponds to the historical concept of Saraya (1982) who said that the use of myths as evidence for explaining the story about the local people in the historical dimension would see the history or the revelations of the past or days before written document. A myth is basic information that is another set of knowledge that leads to understanding the cultural identity of people in the society. Knowledge sets from myths are important components that help to create an in-depth understanding, providing a deep picture about the movement and momentum of the villagers or the local people. It also provides information that is linked to stories that are historically relevant to people in history or related to the past events that still are in the memories of local people. A myth is then regarded as a living history that has been told, playing a role as a set of knowledge that is linked to the present people to know the story in the past.

In addition, it was found that the influence of the creation in the form of imitation which is the nature of the spread of a pattern to the neighboring areas. For instance, the Chao Pho Srinakhon Tao Monument, located at Ban Mueang Tao, Phayakkhaphum Phisai district, Maha Sarakham province which gives an influence in terms of beliefs and forms to the monument of Chao Pho Srinakhon Tao Monument at Ban Nongbua Chaopa, Satuek district, Buriram province. It's found that both areas have a contiguous area and the monument that influenced the spread of the form and the mechanic who lived in the nearby area caused a desire for monuments in their own villages in order to have a monument like the neighboring village. For example, Pho $\mathrm{Pu}$ Khun Si Monument at Ban Saen Si, Kaset Wisai district, Roi Et province which has been influenced by the style and mechanic from nearby areas, namely Ta Salang Phan Monument and Yai Bua Daeng Monument, at Tha Tum district, Surin province. Both of these areas have a contact area, thus, causing the spread of the concept and pattern of creating monuments to each other. This corresponds to the theory of cultural spread by American School, Clark Wissler and Alfred Kroeber who believe the culture will spread from the center to the area where it can go to in the same geography and similar era. From this concept, a group of cultural areas can be seen and it spreads to everywhere where there is no geographical barrier, according to the terrain that humans will be able to reach.
This cultural diffusion theory is consistent with the idea of creating monuments in the Northeastern region in terms of the distribution of concepts and forms in the creation of monuments.

For the current location of the monuments, it's found that most of the monuments are built facing East as it is believed that the East is a sacred direction which corresponds to the concept of the auspicious direction in accordance with the belief in the creation of the E-San Sim (uposatha), Srisuro (1993) who says the reason why a Sim is normally built facing the East is from the fact that the principal Buddha's statue in the Sim is popularly created in a posture of encountering maras which refers to the history of the Lord Buddha who has sought out for enlightenment. As it's been told, once upon a time, before Lord Buddha had enlightened, he went to Bodh Gaya and determined himself to keep meditating in a sitting posture, until even the blood and body were dissolved from the body and would not give up from that posture if the enlightenment was not reached. He turned his face to the East and sat on Vajrasana, a throne paved with grass under the Mahabodhi tree. Even though the devil has come into persecution, he overcame the devils with the daring power, until he was able to enlighten and became the religious founder. Based on this narrative, when sculpting a Buddha's image in an encountering mara posture to be settled on the altar base in the Sim, therefore, favoring to turn his face to the East and this became a tradition that is passed along generation. Consequently, creating a monument facing the East is also the same idea of facing the auspicious direction. The monument shape is also the same for all that looks human-like. This corresponds to Taothong (1996) who says that the figurative art refers to the art that shows the nature, people, animals and things that are seen in nature and presenting the work without any change or distortion from reality because the artist strictly adheres to the principles that appear in nature. The form will present the truth and facts by using stories about nature, the lives of people in various societies. This type of art is also known as concrete art and corresponds to the characteristics of monuments in the Northeastern region, a kind of realistic human image. This group is a group of people in the history that has the source of the original image from the photos and the sculptor would do the best at moulding to make the statue look like the prototype the most. This group is therefore, a monument in the form of a realistic look. For the group of monuments of mythical people that do not exist in the real history, there is only a statement, created according to the ideas of people in the community and according to the imagination of the technician. This corresponds to the aesthetics theory in the mimetic theories which emphasizes universal or natural concept. Considering the value of art in this genre is to consider the level of proximity it looks like the prototypes of 
universality from nature or from life. Therefore, the way of creating art under the mimetic theories is to create according to the most realistic imitation.

For the reflections on E-San society in creating social collective memories, the monument is considered a symbol that reflects the memories of people in the past about important events that make people remember the stories or events that have happened in the past. The creation of monuments is the creation of material culture. The monument will have a story can get back to life again with a ritual for remembrance in order to create the collective memories of people in society. This emphasizes that human beings remember the past with words and images through rituals and celebration that are like a reminder of what had happened in the past. The ritual that is celebrated therefore brings the past events to life again. Therefore, joining the ritual is a way to make the past come true again which corresponds with Connerton (1980) who points out that rituals are not just a matter of expression but a formal action. It comes with design, pattern and is repeatedly held. Various rituals are not always of a formal pattern but sometimes according to the organizer who may emphasize the dominance that people accept in the existing meaning of that ritual. The ritual is not only meant to have a specific meaning only in that occasion but also to infiltrate some messages and meaning in each ritual. This is in line with Songsamphan (2006) who emphasizes that humans can remember the past with words and images through the rituals celebrated as celebration is a reminder of what had happened in the past. The ritual that is celebrated therefore brings the past events to live again. Therefore, joining the ritual is a way to make the past come true again. it's also the linking of the uniqueness of the present person and their ancestors. Arranging and attending a ritual that is celebrated is the intention to remember because the rituals are repeatedly held having a fixed date according to the calendar which is related to past events. Today's rituals or celebrations all have implications for reproducing the social memories for the new generation to absorb and to realize the importance of their legendary ancestors.

For the reflections on E-San society in the monument in aspect of power relations, conflicts and contention in the past, before creating a monument, especially, the legendary group of persons, in the E-San society, there was already paying respect to the local legendary person such as beliefs in the ancestral ghosts. A group of people who have a role in the ritual relating to those monumental figures is Thao Cham and Nang Thiam (spirit operators). Later, when a monument is built to represent the identity of that ancestor, it causes many groups to become more involved. The more famous the monuments are the more people believe in and come to pay homage to worship and wish for achievements, resulting in a large amount of donation income. Money is a factor that makes people want to be part of the management, resulting in the fights to win the opportunity to gain power of monument administration. This reflection is visible in many monuments in the Northeastern region. Controversy over the management of income is generated from the donations of people who worship the monuments in the Northeast and the coming of the local government organizations is also a factor that causes power struggle. In the past, the sacrifice to monuments was an activity that was created by villagers themselves to cooperate in the management and rituals. From wrestling to gain the power to manage the activities and income that have come from more people who have faith in each monument. In the past, it was a group of Thao Cham (spirit operators) who were leaders in rituals. This group tried every way they can to protect the interests of their own. Anyway, there is a new group of more power who also desires for participation in various activities and management of the income, wants to play a role in management. At many monuments, there appears to be a conflict like this in the community regarding the interests of the group itself. This corresponds to the conflict theory according to the concept of Ralf Dahrendorf, a German modern conflict theorist who is a proponent of the idea that society has 2 parts: conflict and the consensus. Both of these are the necessities of each other. Conflicts cannot occur if, before that, there was no reconcilistion before and on the contrary, conflict may lead to reconciliation and integration. Therefore, society cannot exist if there is no conflict and reconciliation. The social conflict that has arisen is a matter of conflict of interest between the superior and the lower-powerful group, i.e., those who have superior power to try to maintain their power while those who have less power or have no power will try to change over time (Soonthronpasuch, 1977).

Reflections on the latentfunction of the monuments to the community, this is a function to control the society. A monument plays a role in controlling the society by controlling it with supernatural power, from faith of people in the community because the old people often said that if anyone does anything wrong or break the Heet 12 tradition, the ancestral spirit will have a punishment. This can cause the people to fear not to make mistakes, it is the control of society for people to behave. This is in line with a concept that says social control, apart from government institutions that play a role in social regulation, religion and beliefs are institutions that are responsible for controlling people's behavior too, whether it is a principle of doctrine in the religion or fear of punishment from supernatural power. In the case of someone misconducts from various social rules. The belief in the ancestral spirits of the E-San people is also the same as it has acted to control the behavior of the villagers, not allowing anyone to behave outside the tradition of society by virtue of the supernatural power of 
ancestral ghosts which results in a society that live in harmony and not behaving guilty against the Heet 12 tradition, this will later bring true peace to the society. In accordance with the structural functionalism theory of Radcliffe-Brown that look at society by comparison with organism which is our body that consists of the system of various organs which each system has its own structure and function. Society is the same to organism, consisting of systems such as family systems, religion, economy, politics, etc. Each of which has a structure and function to make society run smoothly. In each system which is part of the society, it consists of institutions such as religious systems will consist of rituals, beliefs, religious organizations, etc. Each institution will act closely together in order for the system to operate efficiently and to maintain the equilibrium of the society. According to Radcliffe Brown, rituals, beliefs and fairy-tales of the Andaman people are part of the religious system that have the function responsible for enhancing the unity of people in the society. Rituals help to create collective emotions and help control the behavior of members in society within the framework of tradition, creating a unity of society.

For reflections on E-San culture in the monument, this study of monuments in the Northeastern region aims to study the monuments that have been created to be reminiscent of those who have died and have been built as monuments to commemorate the goodness that the person has created for the public, community and the nation. The people in the E-San community believe that the monument has the souls of those ancestral spirits residing in the monument in order to preserve the people in the community for peace. In accordance with the concept of Nartsupha (1998) that describes the worship of the souls of deceased persons or worshiping ancestral spirits that are still present in various villages in Thailand. Although, Thai society has received Buddhism and is based on the main culture, this ghost worship tradition appears clearly in the North and Northeast. People respect the spirits of the clan which are spirits of the ancestors. The worshipers will join the spirit-feasting ceremony at least once a year at the house ranked the first of the family tree which has an ancestral ghost house located at. They believe that feasting a host's spirits will maintain the house and the family members to stay together happily. If anyone doesn't come, it will cause illness to that family. Belief in ancestral spirits is widely spread in the E-San community, especially, in the area where there appears to be Don Pu Ta and where there are monuments built as a place for the ancestral spirits to be able to be seen concretely. In the past, before creating a monument that look human-like, a small shrine was built or in some local places, they used carved wood or a stone to be as a symbol for that particular person. Later, when appearing as a statue of a person with an identity, people can see the face appearance and gestures, this makes the belief in the ancestral spirits more powerful. In accordance with Nankhanti (2015) who said that beliefs and ghosts are the original religion of humanity. At the beginning of the religious development, humans cannot find explanations for natural phenomena such as rain, thunder, lightning, therefore, they believed that everything is caused by a supernatural power. Later, people believed that in nature, there were spirits with sacred powers resided and continuously developing beliefs until accepting Buddhism as an anchor of the mind and integrating faith in harmony to use as a pattern in life. The E-San people's belief in spirits is inherited from their ancestors and when the ancestral monuments were built, it was believed that the spirits of the ancestral spirits came to reside there in the monument, it's even further reinforcing the story of ancestral spirits.

Important findings in this research indicate that, the monument was the creation of a person who had no real identity to be concrete, especially, the monuments of legendary persons of the community. With the belief in ancestral spirits such as the ghost of the Phi Pu Ta which is an important concept used to create monuments and is a unique feature of the creation of local monuments in the Northeast the creation of an abstraction that has only a legendary name to appear as a physical form. This corresponds to Leepreecha (2017) who studied about local and Lanna ethnic monuments indicated that, originally, the villagers built only a Hor Phi (guardian ghost house) or a Suea Mueang (guardian god shrine) that looks like a shrine and a small cabin with a roof and may have a wall surrounded to invite the guardian god to reside there, so, the local people can worship. Without being able to know what the appearance of the goddess that they respected looks like because each of the guardian gods, if they really existed, it should have been a very long time in the past until the present, leaving only the legend. However, when made into a statue, regardless of being a statue in a shrine usually a sitting position on a raised platform, or the creation of a statue of a monument in a standing position on a high altar or with a covering pagoda to prevent damages that may occur from natural disasters. Each statue of the guardian gods makes people have a mutual understanding when they see the gesture, the appearance and the manner in which the sculpture was particularly made. After it has been created to look human-like what would bring the monument to life is to have a story and a myth for the people to tell as well as to have a ritual for the monument to retain the existence of the monument. The ritual that was held is to emphasize the process of creating the identity of the monument through myths and narratives that relate to the history of that community. The ritual arrangement or annual feasting is for people in the community to get to know the origin of the monument's identity through the 
rituals. It is considered that social phenomena that occur with monuments can reflect the E-San society and culture, especially, in the monuments that were created from the legendary persons of the community related to the history and people's way of life in the local community in the Northeastern region.

\section{CONCLUSION}

According to history of monuments built by the concept of local people in E-San that is not a government concept, the first monument in this category was built in 1968 the Chaopho Si Nakhon Tao monument at Ban Mueang Tao, Mueang Tao subdistrict, Phayakkhaphum Phisai district, Maha Sarakham province. After that, many other monuments were then created until the present day. Classification of monuments that are created according to persons can be divided into 2 groups: historical persons and legendary persons. The study found that the use of legendary persons was used to create monuments the most. Current condition of the monuments consists of the location of the monument, it's found that most of the monuments are located in the public area of the community such as the community's ancestral spirit forest (Don $\mathrm{Pu} \mathrm{Ta}$ ) where is normally located on the north side of the community, facing to the East. The monument layout, it was found that there were 2 patterns independent and rectangular layouts, the rectangular is mostly found. The shape of the monument, a human-like shape is mostly found showing gestures in both sitting and standing positions. The materials and construction techniques, materials used are usually cement, stone and brass, applying fresh mortar molding techniques, stone carving and brass casting. For the reflection of E-San society and culture, it was found that the monument can reflect the image of E-San society in 3 aspects: the creation of social collective memories, the power relations, conflict and contention in the management of monuments among people in the community and role and function for the communities, this consists of main function as the monument plays a role in the sanctification of the rituals in the community as well as helping to support the community agriculture cycle. Regarding the latent function, this consists of social control and create the unity of society, while the cultural reflection consists of 2 aspects: beliefs towards the monuments, consisting of a belief that regards the monuments as a sacred place, therefore, there were people who make solemn promises, pay homage, asking for blessings and encouragement as well as beliefs in ancestral spirits, resulting in annual ritual sacrifice ceremony in order to express faith to the monuments, holding rituals. There are both personal rituals and community rituals. Five elements of the ritual consists of: the place for holding the ritual, the ritual person, the object of the ritual, the time of the ritual and ritual processes and sequences.

\section{REFERENCES}

Aruninta, A., 2005. Memorial, Landscape of Memories. Chulalongkorn University, Bangkok, Thailand,.

Connerton, P., 1980. How Societies Remember. 1st Edn., Cambridge University Press, Cambridge, UK., ISBN: 9780521270939, Pages: 121.

Eoseewong, N., 1990. Monument war and the Thai State. Bangkok Art and Culture Centre, Bangkok, Thailand.

Kaewngamprasert, S., 1994. Image of Thao Suranaree in Thai history. M.A. Thesis, Thammasat University, Tha Phra Chan Campus, Bangkok, Thailand.

Khumsupha, M., 2005. [Democracy Monument with Invisible Meanings]. Vibhasa Publishing House, Bangkok, Thailand, Pages: 360 (In Thai).

Leepreecha, P., 2017. Lanna Guardian Gods: From a Guardian Spirit House to Statue, Shrine and Monument. Wanida Printing Ltd., PART, Chiang Mai, Thailand,.

Namkaew, G., 2013. Statues of Heroic King on Elephant and horse. Master's Thesis, Silpakorn University, Bangkok, Thailand.

Nankhanti, A., 2015. Spirits worship of Thai-Nyo: Relations of beliefs and cultural ecology. Ph.D. Thesis, Burapha University, Saen Suk, Thailand.

Nartsupha, C., 1998. Thai Village Culture. Creative Publishing, Bangkok, Thailand,.

Prakit Nontawith, C., 2007. [Politics and Society in Applied Siamese Arts and Architecture in Modern Thai Nationalism]. 2nd Edn., Matichon, Bangkok, Thailand, ISBN: 9789743233237, Pages: 503 (In Thai).

Saraya, D., 1982. Myths \& Legends: A Study of Local History. Pitaksakon Printing, Bangkok, Thailand,.

Songsamphan, C., 2006. [When Women Think of Tentacles: Fighting the Truth of Sex in the House of Representatives]. Kobfai Publishing Project, Bangkok, Thailand, Pages: 211 (In Thai).

Soonthronpasuch, S., 1977. [Contemporary Sociology Theory: Basic Concepts, Social and Cultural Theories]. Samnakphim Kobonwichan, Chiang Mai, Thailand, ISBN: 9789748992709, Pages: 399 (In Thai).

Srisuro, V., 1993. Sim E-Sarn. Maka Press, Bangkok, Thailand.

Taothong, S., 1996. [Principles of Visual Arts]. Witthaya Phat Group Co., Ltd., Bangkok, Thailand, Pages: 156 (In Thai).

Tatiya, M., 2006. [Basic Sculpture]. Emmy Trading Ltd., Part, Bangkok, Thailand, ISBN: 974-94135-7-1, Pages: 160 (In Thai). 